\title{
Estimating Effective Dose of Radiation from Pediatric Cardiac CT Angiography Using a 64-Slice Scanner: New Conversion Factors Relating Dose-Length Product to Effective Dose
}

\author{
Sigal Trattner ${ }^{1}$, Anjali Chelliah ${ }^{2}$, Peter Prinsen, PhD $^{3}$, Carrie B. Ruzal-Shapiro ${ }^{4}$, Yanping \\ $\mathrm{Xu}^{5}$, Sachin Jambawalikar ${ }^{6}$, Maxwell Amurao $^{7}$, and Andrew J. Einstein ${ }^{8,}$ \\ ${ }^{1}$ Department of Medicine, Division of Cardiology, Columbia University, 51 Audubon Ave, New \\ York, NY, 10032, USA, sigal.trattner@columbia.edu, Tel: +1-212-305-4275, Fax: +1- \\ 212-305-4648
}

2Department of Pediatrics, Division of Pediatric Cardiology, Morgan Stanley Children's Hospital, New York Presbyterian - Columbia University Medical Center, 622 West 168th Street. New York, NY, 10032, USA, ac2967@cumc.columbia.edu; Tel: +1-212-342-1560, Fax: +1-212-342-5721

${ }^{3}$ Philips Research, High Tech Campus 34, office 2.059, 5656AE, Eindhoven, The Netherlands Tel: +3164558 2688

${ }^{4}$ Department of Radiology, Columbia University Medical Center, 3959 Broadway, New York, NY 10032, USA, cbr1@columbia.edu, Tel: +1-212-305-7233

${ }^{5}$ Radiological Research Accelerator Facility (RARAF), Center for Radiological Research, Columbia University, 136 S. Broadway, Irvington, NY, 10533, USA, yx2132@columbia.edu, Tel: +1-914-591-9244, Fax: +1-914-591-9405

${ }^{6}$ Department of Radiology, Columbia University Medical Center, 177 Ft. Washington Ave., New York, NY 10032, USA, sj2532@columbia.edu, Tel: +1-212-305-5005

${ }^{7}$ Radiation Safety Office, Columbia University Medical Center, New York, NY 10032, USA, ma3272@columbia.edu, Tel: +1-212-305-0303

${ }^{8}$ Department of Medicine, Cardiology Division, and Department of Radiology, Columbia University Medical Center and New York Presbyterian Hospital, 622 West 168th Street, PH 10-203A, New York, NY, 10032, USA, andrew.einstein@columbia.edu, Tel: +1-212-305-4275, Fax:

$+1-212-305-4648$

\section{Abstract}

Objective-To determine conversion factors enabling accurate estimation of effective dose (ED) for 64-slice cardiac CT angiography in children.

Methods-Anthropomorphic phantoms representative of 1- and 10- year-old children, with 50 metal oxide semi-conductor field-effect transistor (MOSFET) dosimeters placed in organs, were scanned using different clinical routine cardiac scan modes and x-ray tube potentials on a 64-slice

*Corresponding author.

IRB statement: No IRB approval was required for this study. 
CT scanner. Organ doses were used to calculate ED based on weighting factors from International Commission on Radiological Protection Publications (ICRP) 60 and 103. EDs and the scannerreported dose-length products (DLPs) were used to determine conversion factors for each mode. The impact of infant heart rate on ED and conversion factors was also assessed.

Results-Conversion factors using the current ICRP 103 definition of ED averaged 0.099 $\mathrm{mSv} \cdot \mathrm{mGy}^{-1} \cdot \mathrm{cm}^{-1}$ in the 1-year-old phantom, and $0.049 \mathrm{mSv} \cdot \mathrm{mGy}^{-1} \cdot \mathrm{cm}^{-1}$ in the 10 -year-old phantom. The conversion factors were on average 37\% higher than corresponding factors using the older ICRP 60 definition of ED. Varying heart rate did not influence ED or conversion factors.

Conclusions-Conversion factors determined using the current definition of ED, and cardiac rather than chest scan coverage, for a GE a 64-slice contemporary scanner suggest higher radiation doses to children from cardiac $\mathrm{CT}$ than those previously reported when using old chest conversion factors. Additional up-to-date pediatric cardiac CT conversion factors are required for contemporary scanners and different age ranges.

\section{Introduction}

Computerized tomography (CT) is a rapid and accurate tool to diagnose heart disease in children [1-3] and adults [4]. Technological advances in CT that have increased both spatial and temporal resolution [5] have improved the quality of diagnostic images and enhanced our ability to diagnose a variety of conditions. One growing application of CT in children is its use for evaluating congenital cardiac disease. In many practice settings, coronary CT angiography is the primary modality used to evaluate a patient with a suspected coronary artery anomaly. It is also increasingly used as an alternative to MRI and catheter-based angiography in children with congenital heart disease to evaluate such structures as great vessels, systemic and pulmonary veins, and surgical shunts, conduits, and baffles [6, 7].

These technical advances and new applications have fueled dramatic growth in the number of CT scans performed in both adults and children [8,9]. The use of CT in children under 5 years of age, in particular, has reportedly doubled in the United States between 1996 and 2010 [8]. In turn, the more frequent use of CT has increased the population's radiation burden. In children, this trend has been of particular concern; data from large epidemiological studies of children exposed to CT scans demonstrate an increased cancer risk in comparison to their non-exposed peers [10-12], notwithstanding some controversy surrounding the interpretation of these data [13]. Epidemiology-based risk models suggest that pediatric CT patients bear a significantly increased lifetime risk of developing a radiation-related cancer when compared to adults, owing at least in part to the greater radiosensitivity and longer life expectancy of children. These models have found even higher radiation risk in infants compared to older children [12].

Probably the most widely-used dose metric for quantifying radiation from medical imaging is the effective dose (ED). ED is defined in International Commission on Radiological Protection (ICRP) Publication 103 [14] as a weighted average of organ doses, with these organ weights chosen based on the relative radiosensitivity of each organ, and therefore ED reflects radiation risk to a population. In CT, ED is commonly estimated by multiplying a console-reported dose index, the dose-length product (DLP), by a conversion factor, also 
referred to as a k-factor. The DLP reported by the scanner is based on prior dosimetry measurements performed using a standardized cylindrical polymethyl-methacrylate (PMMA) phantom, referred to as a computed tomography dose index (CTDI) phantom. Two standard CTDI phantoms, with diameters of $16 \mathrm{~cm}$ and $32 \mathrm{~cm}$, are in use; the size of the phantom used is generally chosen based on patient size and region of the body scanned, although by a specification of the International Electrotechnical Commission since 2012 [15], a $32 \mathrm{~cm}$ CTDI phantom should be used for all pediatric body scans.

Various conversion factors have been published for different types of pediatric CT scans performed across a range of ages. In some cases, including factors adopted as standards by professional societies $[16,17]$, these conversion factors were derived using older CT technology and/or an outdated definition of ED prescribed in ICRP Publication 60 [18]. An updated list of conversion factors has subsequently been developed by Deak et al [19], based on multi-slice scanner models and ICRP 103 weights. However, cardiac conversion factors were not included in either these standard lists of conversion factors or those of Deak et al. Thus, cardiac scan EDs are typically estimated using chest conversion factors [7, 20].

Only two studies have attempted to determine conversion factors for pediatric cardiac CT. These studies were conducted on a 16-slice GE LightSpeed scanner, for a 5-year old phantom [21], and on a 320-slice Toshiba Aquilion ONE scanner, for 1- and 5-year -old phantoms [22]. However, 16-slice scanners are no longer used for coronary CT angiography (and in fact no longer reimbursed by payers), while state-of-the-art 320-slice scanners, which uniquely utilize a volume scan mode for coronary CT angiography, are not widely available. In this study conversion factors for pediatric cardiac $\mathrm{CT}$ are determined using a GE 64-slice scanner.

We determine cardiac conversion factors for 1- and 10- year-old children for a commonlyused 64-slice scanner, using an experimental setup that includes anthropomorphic phantoms and MOSFET dosimeters to accurately estimate ED. Conversion factors are derived for different cardiac protocols that are used in daily routine scans. In addition, since previous studies have suggested an impact of heart rate on ED in some scenarios, particularly related to tube current modulation [23], we also examined the effect of different heart rates on ED and conversion factors for the 1-year-old phantom.

\section{Methods}

\section{Phantoms}

Anthropomorphic phantoms representative of 1-year-old (ATOM 704; CIRS, Norfolk, VA; height $75 \mathrm{~cm}$, weight $10 \mathrm{~kg}$ ) and 10-year-old (ATOM 706; CIRS, Norfolk, VA; height 140 $\mathrm{cm}$, weight $32 \mathrm{~kg}$ ) children were used. These phantoms are physically and radiographically similar to a human body and are therefore adequate for simulating a human scan. The phantoms are made of tissue-equivalent materials (polymers and resins) of the body's anatomy and include attenuation characteristics at diagnostic photon energies. The simulated organs include soft tissue, spinal cord, spinal discs, lungs, brain, and bone. Photon attenuation values are within $3 \%$ of actual tissue. The phantoms consist of $25 \mathrm{~mm}$-thick 
transverse slices containing several 5-mm-diameter holes in which the MOSFET dosimeters can be placed using tissue-equivalent holders.

\section{Dosimeters}

A mobile MOSFET dose verification system (TN-RD-70W; Best Medical, Ottawa, Canada) with ten readers and high-sensitivity MOSFETs (TN-1002RD-H; Best Medical, Ottawa, Canada) were used for organ dosimetry. Each reader enabled 5 MOSFET readouts, and 50 MOSFETs were used in total for organ dosimetry measurements. MOSFET readouts were in voltage, communicated through the readers to two PC laptops via two wireless Bluetooth devices. MOSFET calibration was performed for translating voltage to exposure ( $\mathrm{mV}$ to mGy), using an ion chamber (10X6-3CT; Radcal, Monrovia, California) with a control unit (Accu-Dose 2186; Radcal) and a standard $32 \mathrm{~cm}$ diameter PMMA CTDI phantom of $14 \mathrm{~cm}$ depth (West Physics Consulting). Calibration factors (CFs) were measured for three energy levels that were used for cardiac scan modes: 80, 100 and $120 \mathrm{kVp}$.

\section{Scan Details}

Scans were performed on a GE LightSpeed VCT XTe (GE Healthcare, Waukesha, WI) 64slice scanner and included the following coronary CT angiography scan modes: axial scans with no padding, axial scans with 100 milliseconds (ms) padding, helical scans, and helical scans with ECG-based tube current modulation (TCM) with current maximized from $70-80 \%$ of the R-R cardiac cycle. In addition, a calcium scoring scan protocol was performed for the 10-year-old phantom. Following settings used for standard clinical scans, we performed scans with 80 and $100 \mathrm{kVp}$ tube potential for the 1-year-old phantom, and added $120 \mathrm{kVp}$ scans for the 10 -year-old phantom.

Helical scan pitch values were automatically selected by the scanner based upon heart rate and were set to a value between 0.20 and 0.24 . Calcium score scans for the 10-year-old phantom were tested for $32 \times 0.625$ and $64 \times 0.625$ collimations. For both phantoms, a small scan field of view (SFOV) was used. Appropriate scan lengths were chosen by consensus of an adult cardiologist (AJE) and a pediatric cardiologist (AC) according to scout images and were set to $69.4 \mathrm{~mm}$ for the 1-year-old phantom and $105.5 \mathrm{~mm}$ for the 10 -year-old phantom.

We used a "chicken heart" electrocardiogram simulation device to simulate an ageappropriate heart rate of $60 \mathrm{bpm}$ for the 10 -year-old phantom and $100 \mathrm{bpm}$ at the first set of experiments for the 1-year-old phantom. For the 1-year-old, we also studied the impact of varying heart rates on ED, by repeating scans at rates of $90,110,130$ and $150 \mathrm{bpm}$ in six protocol scan modes.

\section{Organ doses and ED calculation}

Fifty MOSFETs were placed in each phantom (Fig 1), positioned in organs that contribute to the ED according to ICRP 103[14] (and ICRP 60 [24]) as detailed in Table 1.

A MOSFET voltage reading in tissue, $X_{\text {tissue }}$, was translated to dose, $D_{\text {tissue }}$, as follows:

$$
D_{\text {tissue }}=f_{\text {tissue }} \cdot C F \cdot X_{\text {tissue }}
$$


where $C F$ is the calibration factor in units of $\mathrm{mGy} / \mathrm{mV} ; f_{\text {tissue }}$ is the f-factor which converts exposure to dose-in-tissue and is defined as:

$$
f_{\text {tissue }}(\bar{E})=\frac{\left(\frac{\mu e n}{\rho}\right)_{\text {tissue }}}{\left(\mu \frac{\mu n}{\rho}\right)_{\text {air }}} .
$$

Here both exposure and dose-in-air are reported in units of $\mathrm{mGy}$, and hence the f-factor is simply the ratio of the mass energy-absorption coefficients, $\mu_{\text {en/ } \rho}$, of a certain organ tissue to air. Mass energy-absorption coefficients were taken from National Institute of Standards and Technology (NIST) tabulated data [25] (http://www.nist.gov/pml/data/xraycoef/index.cfm) for the effective energy of X-rays used $(\bar{E})$. The Monte Carlo N-particle radiation transport program MCNP/MCNPX (Los Alamos National Laboratory, Los Alamos, NM) was used to simulate the effective energy based on the phantom, voltage used $(80,100,120 \mathrm{kVp})$, and characteristics of the tube including the filtration employed. For each organ that was available in the NIST tables, the mass energy- absorbance coefficient was extracted, as well as the air energy-absorbance coefficient, and their ratio was calculated for $\mathrm{f}$-factor determination. Due to coarse energy levels in the NIST tables we used cubic spline interpolation to decide the right mass energy-absorbance coefficient.

Relevant tissues in the NIST tables for which information was extracted included the breast, lung, bone, brain, ovary, testis and soft tissue; the value used for bone surface was that of bone and the value used for red bone marrow was that of soft tissue. For all other organs, the f-factor of soft tissue was used. f-factor values for effective energies of the different tube potentials are detailed in Table 1.

Organ doses in larger or highly radiosensitive organs such as lungs were determined based on measurements in multiple MOSFETs (Table 1), and an average was calculated to estimate the organ absorbed doses. Bone marrow doses were measured in different MOSFET locations, and a weighted average was determined according to their mass as specified by Eckerman et al [26]. Similarly, an average dose was calculated for bone surface. While the definition of ED refers to both female and male phantoms, in prepubertal pediatric patients, only a single type of phantom is relevant. An average between testes and ovary readings was calculated to represent both genders' gonad organs. Organ doses were weighted by the relevant tissue weighting factor and summed over all organs to determine the EDs according to both ICRP 103 and ICRP 60 definitions.

Scans were repeated mostly 10 times. The number of repetitions was chosen based on a sample size derived for MOSFET dosimetry experimental design for calculating ED on adult (female and male) phantoms [27]. A mean reading was taken per each MOSFET position for calculations.

For all scans, in both 1- and 10-year-old phantoms, conversion factors were determined using DLP based on a $32 \mathrm{~cm}$ CTDI phantom, as determined by the scanner console software. DLP values were recorded for each repetition, from the dose reports, post scanning. ED was 
calculated per scan mode using the average organ doses, and conversion factors were determined for each scan mode by dividing this ED by the DLP (average) for the scan mode.

\section{Validating the use of 50 MOSFETs}

While the use of 20 MOSFETs within a phantom was validated against thermoluminescent dosimeters (TLDs) by Yoshizumi et al [28], we verified the use of 50 MOSFETs at a time, specifically, examining the influence of the copper wires of 50 MOSFETs on the effective dose and thus on the conversion factors. For this task, we re-ran all 8 experiments reported for the 1-year-old phantom, dividing each of the 8 experiments into three sub-experiments, such that in each sub-experiment, the phantom had only 16-17 MOSFETs placed in organs, with the remaining MOSFETs removed, thus reducing the number of wires threefold compared to the use of 50 MOSFETs at a time. All three sub-experiments were run similarly, with the same protocol parameters, the same scan location (and length), and the same position of the phantom.

\section{Heart rate effect measurements}

Six scan mode protocols were used for scanning the 1-year-old phantom with four different heart rates: 90, 110, 130 and $150 \mathrm{bpm}$. Scan modes used for this purpose included axial, axial with $100 \mathrm{msec}$ padding, helical (single-beat reconstruction [Snapshot Segment], 2-beat multicycle reconstruction [Snapshot Burst], and up to 4-beat multicycle reconstruction [Snapshot Burst Plus]) and helical with TCM, with tube potential of $80 \mathrm{kVp}$. For each scan mode, parameter values $(\mathrm{kVp}, \mathrm{mA}$, rotation time, collimation, scan length and pitch for helical modes) were kept constant, while the heart rate was changed.

The effect of heart rate on dose was examined by comparing the resulting EDs and conversion factors of the same scan mode among the different heart rates chosen. The coefficient of variation $(\mathrm{CoV})$ of $\mathrm{ED}$ and the $\mathrm{CoV}$ of the conversion factors were calculated and expressed in percentage for indication of the amount of variability.

\section{Results \\ Conversion factors}

Table 2 lists cardiac conversion factors derived from 1- and 10-year-old phantoms for 14 types of scans (12 CT angiogram protocols and 2 calcium scoring protocols), based on scanner-reported DLP values for a $32 \mathrm{~cm}$ CTDI phantom, for both the ICRP 103 and ICRP 60 definitions of ED. For the 1-year-old phantom, conversion factors varied little between scan modes and tube potentials, ranging from 0.093 to 0.103 with an average of 0.099 $\mathrm{mSv} \cdot \mathrm{mGy}^{-1} \cdot \mathrm{cm}^{-1}$ using the ICRP 103 definition. For the 10-year-old, conversion factors varied modestly between axial CTA (range $0.054-0.057 \mathrm{mSv} \cdot \mathrm{mGy}^{-1} \cdot \mathrm{cm}^{-1}$ using ICRP 103 definition) and helical CTA (range 0.042-0.044 $\mathrm{mSv} \cdot \mathrm{mGy}^{-1} \cdot \mathrm{cm}^{-1}$ ); the conversion factor for calcium scoring was $0.046 \mathrm{mSv} \cdot \mathrm{mGy}^{-1} \cdot \mathrm{cm}^{-1}$. These conversion factors were on average $37 \%$ higher than those obtained using the older ICRP 60 definition of ED (Table 2).

Figure 2 depicts the weighted equivalent doses to individual organs, expressed as the percentage of ED, computed according to ICRP 103 and ICRP 60 protocols, for 1- and 10- 
year-old phantoms. The breast and lung together account for about $60-70 \%$ of the ED in both age groups. When using the ICRP 103 metrics, breast tissue received the highest radiation dose, while with ICRP 60 , the lungs received the largest amount of radiation.

Table 3 demonstrates the ED and conversion factor at differing heart rates for the six scan modes used. For each scan protocol, the $\mathrm{CoV}$ was calculated for conversion factors calculated across the range of heart rates evaluated. For most protocols and by either IRCP definition, CoVs measured less than $5 \%$. Thus, conversion factors did not significantly vary for identical scans performed at different heart rates.

Conversion factors derived from the 1-year-old phantom, based on dosimetry experiments performed with three sets of measurements, each with 16-17 MOSFETs placed, are presented in Table 4, similar to the conversion factors in Table 2. Percent differences were determined with respect to the conversion factors results that were based on dosimetry using 50 MOSFETs per measurement (Table 2). The conversion factors based on dosimetry using fewer MOSFETs are only slightly different from the conversion factors obtained using the 50 MOSFETs. The absolute value of the percent difference averaged $2.8 \%$ using the ICRP 103 definition of effective dose and by $2.6 \%$ using the ICRP 60 definition. No experiment evidenced a percent difference of more than $7.7 \%$. These results demonstrate that the 50 MOSFET copper wires had negligible impact on the calculation of conversion factors, thus validating their simultaneous use.

\section{Discussion}

Accurate dosimetry using appropriate conversion factors is essential to monitoring and reducing radiation exposure from $\mathrm{CT}$ scans. This study is the first to report cardiac conversion factors for GE 64-slice pediatric CT. Using MOSFET dosimeters, we determined cardiac CT conversion factors in experiments performed in physical anthropomorphic phantoms representing 1- and 10-year-old children. Our results demonstrate considerably similar values compared to Podbersky et al's [22] cardiac conversion factors, in spite of some difference in scan length, and higher values than previously published chest conversion factors (Table 5) used for estimating ED for cardiac scans. Secondarily, we found that varying heart rate from 90 to $150 \mathrm{bpm}$ in otherwise similar scans on a 1-year-old phantom had negligible effects on ED and thus on conversion factor calculations.

In current clinical practice, the most widely used pediatric CT conversion factors, reported by Shrimpton et al [18], and incorporated into guidelines of the European Commission [17] and American Association of Physicists in Medicine [16], do not include a conversion factor specific to cardiac CT. Instead, chest conversion factors of $0.026 \mathrm{mSv} \cdot \mathrm{mGy}^{-1} \cdot \mathrm{cm}^{-1}$ in a 1year-old and $0.013 \mathrm{mSv} \cdot \mathrm{mGy}^{-1} \cdot \mathrm{cm}^{-1}$ for a 10-year-old $[7,20,30]$ are often used. These conversion factors are based on the older ICRP Publication 60 definition of ED and were derived using single-slice scanners and a $16 \mathrm{~cm}$ diameter CTDI phantom. The organ and tissue weighting factors that underlie calculations of the ED and therefore conversion factors have been updated from ICRP 60 to ICRP 103. One major change in the ICRP 103 affecting cardiac ED was an increase in breast tissue weight factor from 0.05 to 0.12 . In our study, conversion factors based on the ICRP 103 definition of ED are on average 37\% higher than 
conversion factors calculated using the ICRP 60 definition (Table 5). Thus, standard chest conversion factors based on outdated ICRP 60 tissue weighting factors significantly underestimate scan ED and patient radiation exposure.

Using these older chest conversion factors not only underestimates the impact of radiation upon breast tissue that but also assumes a different scan coverage area than cardiac CT that may further underemphasize the amount of breast tissue irradiated. Chest conversion factors are derived assuming a craniocaudal scan length that spans the entire chest, typically $12 \mathrm{~cm}$ in a 1-year-old, $20 \mathrm{~cm}$ in a 10-year-old, and $27 \mathrm{~cm}$ in an adult. A cardiac CT scan is performed with more limited craniocaudal z-axis coverage that is centered around the level of the breasts. Therefore, in a (shorter) cardiac scan, although the identical breast tissue is irradiated as in a chest CT scan, ED calculations determined using a chest conversion factor would inaccurately reflect less breast irradiation per length scanned than would calculations using a cardiac scan-specific conversion factor, and thereby underestimate the ED [31].

Finally, using a $32 \mathrm{~cm}$ rather than a $16 \mathrm{~cm}$ diameter phantom as a reference for CTDI also affects the DLP and therefore the ED. Subsequent to the current conversion factors [15, 16] developed by Shrimpton et al $[18,32]$ based on a $16 \mathrm{~cm}$ phantom, the International Electrotechnical Commission [15], and consequently manufacturers, have moved towards reporting DLP calculated based on a $32 \mathrm{~cm}$ phantom for all pediatric body scans, including cardiac CT. For a comparable body-region scan, the DLP determined from a $32 \mathrm{~cm}$ phantom has been reported to be about half the value determined from a $16 \mathrm{~cm}$ phantom [22] [33]. Thus a conversion factor determined from MOSFET-derived organ doses and using DLP measured in a $32 \mathrm{~cm}$ phantom, would be twice as large as one using DLP measured in a 16 $\mathrm{cm}$ phantom. This point highlights the importance of choosing a conversion factor appropriate for the CTDI phantom size that the scanner uses to determine the DLP. Even so, our estimated cardiac conversion factor for a 10 -year-old patient, $0.0487 \mathrm{mSv} \cdot \mathrm{mGy}^{-1} \cdot \mathrm{cm}^{-1}$, is considerably more than twice the $0.0130 \mathrm{mSv} \cdot \mathrm{mGy}^{-1} \cdot \mathrm{cm}^{-1}$ reported by Shrimpton and colleagues, thus exceeding what would be expected from our choice of a $32 \mathrm{~cm}$ rather than $16 \mathrm{~cm}$ phantom, and reflecting the updated definition of ED, the cardiac scan range, newer technology, etc. It is useful to note that the data for 1-year-old and 10-year-old phantoms from Shrimpton et al, normalized to a 32-cm phantom $\left(0.049,0.025 \mathrm{mSv} \cdot \mathrm{mGy}^{-1} \cdot \mathrm{cm}^{-1}\right)$, compare favorably with the results from Deak et al $\left(0.0443,0.0221 \mathrm{mSv} \cdot \mathrm{mGy}^{-1} \cdot \mathrm{cm}^{-1}\right)$, respectively. The compared conversion factors are based on similar chest regions and on ICRP 60 weighting factors, further demonstrating the factor of 2 between conversion factors for 16- and 32-cm phantoms.

The only published pediatric cardiac conversion factor available for comparison to our data (Table 5), from Podbersky et al [22], is that for a 1-year-old phantom, based on similar methodology to our study, using ICRP 103 weighting factors and derived from a 320-slice volume scanner [22]. However, Podbersky et al [22] used a $16 \mathrm{~cm}$ CTDI phantom in experiments involving the 1-year-old phantom, whereas in our experiments we determined cardiac conversion factors based on a $32 \mathrm{~cm}$ CTDI phantom. To account for this difference, we applied Podbersky's normalization factor of 1.9 to their conversion factors. Normalizing to $32 \mathrm{~cm}$, their average factor then became $0.092 \mathrm{mSv} \cdot \mathrm{mGy}^{-1} \cdot \mathrm{cm}^{-1}$ for a DLP based on a 32 $\mathrm{cm}$ CTDI phantom, similar to our average conversion factor of $0.099 \mathrm{mSv} \cdot \mathrm{mGy}^{-1} \cdot \mathrm{cm}^{-1}$ 
(Table 5). Indeed, Podbersky et al used a longer scan length than we did (10 vs. $6.9 \mathrm{~cm})$ for the 1-year-old cardiac scan. Repeating four experiments (1-year-old phantom, $80 \mathrm{kVp}$ ) with a scan length of $10.4 \mathrm{~cm}$, we found that conversion factors were lower on average in $10 \%$ compared with conversion factors of $6.9 \mathrm{~cm}$ scan length; with these results, we find even better agreement between the two studies in terms of conversion factors.

Our results, which incorporate the updated assumptions outlined above and which are similar, in the conversion factors of 1-year-old cardiac scans, to Podbersky et al's 320 slice scanner study, demonstrate that EDs from cardiac CT may be dramatically underestimated when based upon the older chest conversion factors. These results further emphasize the need to use updated conversion factors that are designated specifically for the cardiac region, in order to more accurately evaluate the ED from a cardiac scan. This underestimation is of significant clinical importance in the pediatric population. Using our cardiac-specific conversion factors can significantly alter one's perception of the balance of benefits and risks of cardiac $\mathrm{CT}$ in a pediatric population. For example, Ou and colleagues [1] compared the safety and accuracy of CT angiography to that of invasive coronary angiography in a series of 130 children undergoing 64-slice coronary CTA after the arterial switch operation. Using European Commission chest conversion factors, they reported a median ED of 4.5 $\mathrm{mSv}$ for CTA, slightly higher than the $3.1 \mathrm{mSv}$ median ED of invasive coronary angiography. The authors concluded based on this comparison that "the disadvantage of a higher radiation dose seems to be more than offset by the improved safety in terms of cardiovascular complications." Were a cardiac-specific conversion factor used, however, the calculated ED would increase to nearly $16 \mathrm{mSv}$. This significant level of radiation exposure would have made the choice between CT angiography and cardiac catheterization much less clear and might have potentially even altered the authors' conclusions.

This study has some limitations. The use of a phantom to represent a large, heterogeneous population is inherently limited, since a phantom represents a normative average size of an age group. Regardless, using phantoms rather than simulations, as is done in Monte Carlo methods, has the advantage of using an actual scanner and actual scans. The use of simulations is hampered by incomplete knowledge of scanner parameters, which are not fully disclosed for proprietary reasons.

Additionally, this work dealt with only two pediatric phantom sizes, representing 1- and 10year- old children, which was based upon availability. Thus, our results are not fully representative of the broad spectrum of infant, child, and adolescent patient sizes; we hope in future studies to broaden the scope of this work by utilizing a wider range of pediatric phantom sizes in a variety of scanner types.

Furthermore, our conversion factors were calculated based on an experimental setup using MOSFETs for discrete measurements of organ radiation. Experimental measurements encompass uncertainties of the MOSFET devices, of their calibration process and of singlepoint based dose approximations. However, the accuracy of MOSFET technology in assessing CT organ doses has been previously validated [28, 34]. To maximize accuracy, we have used a large number of MOSFETs to evaluate radiation, and performed repeated scans 
to control for the effects of measurement variation. The effect of using 50 MOSFETs at the same time on the conversion factors was tested and found to be negligible.

Yet another limitation of the assumptions underlying our conversion factor calculations is that ED is calculated using ICRP's definition of ED incorporating tissue weighting factors determined primarily from adults. Specifically, ICRP's tissue weighting factors represent mean values for humans over both sexes and over all ages [14]. As radiosensitivity reduces with time [35], averaging over the entire population can potentially underestimate risks in children. The generality of ED, which can characterize radiation exposure in a wide range of populations and exposure scenarios, is one of its great strengths, but is also a limitation in terms of its use in gauging risk to children. Using age- and scanner-specific conversion factors potentially improves ED's utility as a tool which more accurately reflects radiation risk for children.

Finally, there are two sizes of CTDI phantoms that are commercially available, the 16 and 32 diameter $\mathrm{cm}$ phantoms. In this study we have used the $32 \mathrm{~cm}$ phantom for both 1- and 10year old phantom scans, as this is the current international standard and thus scanner software automatically calculates DLP based on this size. While this $32 \mathrm{~cm}$ phantom is a reasonable reflection of habitus for a 10 -year-old, $32 \mathrm{~cm}$ overestimates the circumference of a 1-year-old's chest. A toddler's chest and head circumference are roughly equal at 1 year of age; therefore, per CDC growth charts, an average toddler's chest circumference measures approximately $46 \mathrm{~cm}$, which translates to a diameter of $14.6 \mathrm{~cm}[36,37]$. Thus while using a $16 \mathrm{~cm}$ phantom for DLP determination would more accurately reflect body scanning in a 1 year old child, this would be inconsistent with current standards determined by the International Electrotechnical Commission. Perhaps these standards require reconsideration in the case of very young children.

\section{Conclusions}

Cardiac-specific conversion factors are lacking for estimating ED for children for current CT scanners. In this work, cardiac conversion factors for 1- and 10-year-old children were estimated on a GE 64-slice scanner, yielding averages of 0.099 and $0.049 \mathrm{mSv} \cdot \mathrm{mGy}^{-1} \cdot \mathrm{cm}^{-1}$, respectively. These factors are higher than any chest conversion factor that has been previously published and are similar to cardiac conversion factors that were previously published for a 1-year-old-phantom [22]. The results suggest that radiation doses in pediatric cardiac CT have been systematically underestimated compared to using the old chest conversion factors.

To enable a more accurate and clinically relevant estimate of ED for pediatric cardiac CT, additional conversion factors are required that are based on cardiac and not chest scan coverage and that are generated in a uniform fashion, using a CTDI phantom compatible with international standards, incorporating the current ICRP 103 definition of ED, and utilizing contemporary multislice CT scanners. While heart rate was not found to significantly affect conversion factors, accuracy may be further improved by using factors specific to scanner model, scan protocol type, and specific age range. 


\section{Acknowledgments}

The authors thank Alexander Sheldon Herbert, Tony Zapata and Richard Maldonado for their valuable assistance.

Disclosures: Supported by NIH-NHLBI grant R01 HL109711. Supported as well by a Herbert Irving Associate Professorship and as a Victoria and Esther Aboodi Cardiology Researcher (Dr. Einstein). Dr. Trattner has received institutional research grants for other investigator-initiated studies from Philips Healthcare. Dr. Einstein has received institutional research grants for other investigator-initiated studies from GE Healthcare, Philips Healthcare, Spectrum Dynamics, and Toshiba America Medical Systems.

\section{Bibliography}

1. Ou P, Celermajer DS, Marini D, et al. Safety and accuracy of 64-slice computed tomography coronary angiography in children after the arterial switch operation for transposition of the great arteries. JACC Cardiovasc Imaging 2008 1:331-339 [PubMed: 19356445]

2. Meinel FG, Huda W, Schoepf UJ, et al. Diagnostic accuracy of CT angiography in infants with tetralogy of Fallot with pulmonary atresia and major aortopulmonary collateral arteries. J Cardiovasc Comput Tomogr 2013 7:367-375 [PubMed: 24331932]

3. Xu J, Zhao H, Wang X, et al. Accuracy, image quality, and radiation dose of prospectively ECGtriggered high-pitch dual-source CT angiography in infants and children with complex coarctation of the aorta. Acad Radiol 2014 21:1248-1254 [PubMed: 25097011]

4. Hulten E, Pickett C, Bittencourt MS, et al. Outcomes after coronary computed tomography angiography in the emergency department: a systematic review and meta-analysis of randomized, controlled trials. JACC 2013; 61:880-892 [PubMed: 23395069]

5. Halliburton S, Arbab-Zadeh A, Dey D, et al. State-of-the-art in CT hardware and scan modes for cardiovascular CT. J Cardiovasc Comput Tomogr 2012; 6:154-163 [PubMed: 22551595]

6. Han BK, Lesser AM, Vezmar M, et al. Cardiovascular imaging trends in congenital heart disease: a single center experience. J Cardiovasc Comput Tomogr 2013; 7:361-366 [PubMed: 24331931]

7. Gherardi GG, Iball GR, Darby MJ, Thomson JD. Cardiac computed tomography and conventional angiography in the diagnosis of congenital cardiac disease in children: recent trends and radiation doses. Cardiol Young 2011; 21:616-622 [PubMed: 21733206]

8. Miglioretti DL, Johnson E, Williams A, et al. The use of computed tomography in pediatrics and the associated radiation exposure and estimated cancer risk. JAMA Pediatr 2013; 167:700-707

[PubMed: 23754213]

9. Dorfman AL, Fazel R, Einstein AJ, et al. Use of medical imaging procedures with ionizing radiation in children: a population-based study. Arch Pediatr Adolesc Med 2011; 165:458-464 [PubMed: 21199972]

10. Pearce MS, Salotti JA, Little MP, et al. Radiation exposure from CT scans in childhood and subsequent risk of leukaemia and brain tumours: a retrospective cohort study. Lancet 2012; 380:499-505 [PubMed: 22681860]

11. Mathews JD, Forsythe AV, Brady Z, et al. Cancer risk in 680000 people exposed to computed tomography scans in childhood or adolescence: data linkage study of 11 million Australians. BMJ 2013; 346:f2360 [PubMed: 23694687]

12. Huang WY, Muo CH, Lin CY, et al. Paediatric head CT scan and subsequent risk of malignancy and benign brain tumour: a nation-wide population-based cohort study. BJC 2014; 110:2354-2360 [PubMed: 24569470]

13. Journy N, Rehel JL, Ducou Le Pointe H, et al. Are the studies on cancer risk from CT scans biased by indication? Elements of answer from a large-scale cohort study in France. BJC 2015; 112:185193 [PubMed: 25314057]

14. ICRP Publication 103. The 2007 Recommendations of the International Commission on Radiological Protection. Ann ICRP 2007; 37:1-332

15. IEC 60601-2-44, Medical electrical equipment - Part 2-44:Particular requirements for the basic safety and essential performance of X-ray equipment for computed tomography In: Edition 3.1: IEC, 2012 
16. AAPM. The measurement, reporting, and management of radiation dose in CT, AAPM Report No. 96. In: AAPM Report No 96, 2008

17. Bongartz G, Golding SJ, Jurik AG, et al. European Guidelines for Multislice Computed Tomography. Funded by the European Commission. Contract number FIGM-CT2000-20078-CTTIP, 32004

18. Shrimpton PC, Hillier MC, Lewis MA, Dunn M. National survey of doses from CT in the UK: 2003. BJR 2006; 79:968-980 [PubMed: 17213302]

19. Deak PD, Smal Y, Kalender WA. Multisection CT protocols: sex- and age-specific conversion factors used to determine effective dose from dose-length product. Radiology 2010; 257:158-166 [PubMed: 20851940]

20. Han BK, Lindberg J, Overman D, Schwartz RS, Grant K, Lesser JR. Safety and accuracy of dualsource coronary computed tomography angiography in the pediatric population. J Cardiovasc Comput Tomogr 2012; 6:252-259 [PubMed: 22732198]

21. Hollingsworth CL, Yoshizumi TT, Frush DP, et al. Pediatric cardiac-gated CT angiography: assessment of radiation dose. AJR 2007; 189:12-18 [PubMed: 17579144]

22. Podberesky DJ, Angel E, Yoshizumi TT, et al. Radiation dose estimation for prospective and retrospective ECG-gated cardiac CT angiography in infants and small children using a 320-MDCT volume scanner. AJR 2012; 199:1129-1135 [PubMed: 23096189]

23. Jakobs TF, Becker CR, Ohnesorge B, et al. Multislice helical CT of the heart with retrospective ECG gating: reduction of radiation exposure by ECG-controlled tube current modulation. Eur Radiol 2002; 12:1081-1086 [PubMed: 11976849]

24. ICRP Publication 60. The 1990 Recommendations of the International Commission on Radiological Protection. Ann ICRP 1991; 21:1-201

25. Hubbel JH, Seltzer SM. Tables of X-Ray Mass Attenuation Coefficients and Mass EnergyAbsorption Coefficients. http://www.nistgov/pml/data/xraycoef/index.cfm1996, July 2015

26. Eckerman KF, Bolch WE, Zankl M, Petoussi-Henss N. Response functions for computing absorbed dose to skeletal tissues from photon irradiation. Radiat Prot Dosim 2007; 127:187-191

27. Trattner S, Cheng B, Pieniazek RL, Hoffmann U, Douglas PS, Einstein AJ. Sample size requirements for estimating effective dose from computed tomography using solid-state metaloxide-semiconductor field-effect transistor dosimetry. Med Phys 2014; 41:042102 [PubMed: 24694150]

28. Yoshizumi TT, Goodman PC, Frush DP, et al. Validation of metal oxide semiconductor field effect transistor technology for organ dose assessment during CT: comparison with thermoluminescent dosimetry. AJR 2007; 188:1332-1336 [PubMed: 17449779]

29. Alessio AM, Phillips GS. A pediatric CT dose and risk estimator. Pediatr Radiol 2010; 40:1816182 [PubMed: 20623277]

30. Lee YW, Yang CC, Mok GSP, Wu TH. Infant Cardiac CT Angiography with 64-Slice and 256Slice CT: Comparison of Radiation Dose and Image Quality Using a Pediatric Phantom. PLoS ONE 2012; 7:e49609 [PubMed: 23185380]

31. Huda W, Tipnis S, Sterzik A, Schoepf UJ. Computing effective dose in cardiac CT. Phys Med Biol 2010; 55:3675-3684 [PubMed: 20530853]

32. Shrimpton PC, Wall BF. Reference Doses for Paediatric Computed Tomography. Radiat Prot Dosim 2000; 90:249-252

33. Nickoloff E Current adult and pediatric CT doses. Pediatr Radiol 2002; 32:250-260 [PubMed: 11956706]

34. Jones AK, Pazik FD, Hintenlang DE, Bolch WE. MOSFET dosimeter depth-dose measurements in heterogeneous tissue-equivalent phantoms at diagnostic X-ray energies. Med Phys 2005; 32:3209_ 3213 [PubMed: 16279074]

35. Brenner DJ, Hall EJ. Computed tomography--an increasing source of radiation exposure. N Engl J Med 2007; 357:2277-2284 [PubMed: 18046031]

36. Duderstadt K Pediatric physical examination an illustrated handbook, 2nd ed. St. Louis: Mosby, 2014:366 S

37. Centers for Disease Control and Prevention NCfHS, http://www.cdc.gov/growthcharts/. CDC growth charts: United States. In, 5 30, 2000 


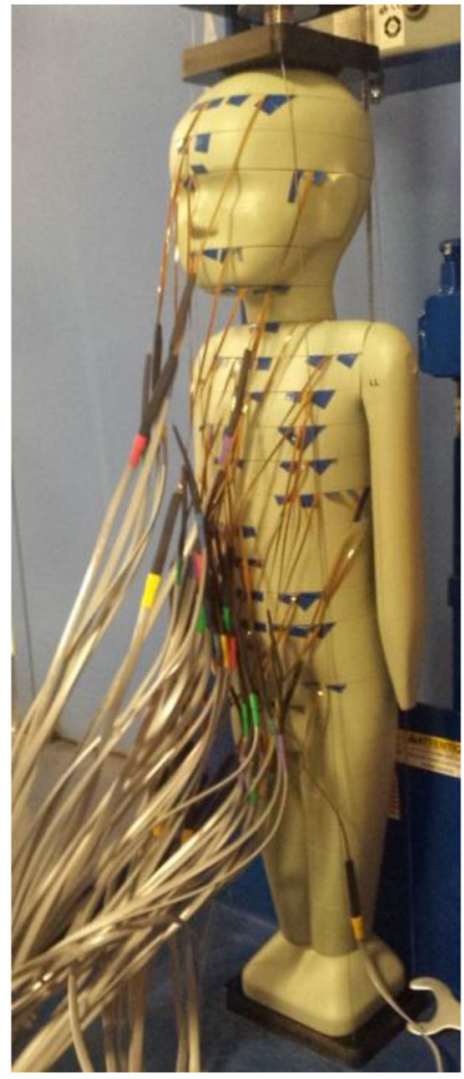

Fig 1:

Anthropomorphic pediatric phantom (1-year-old) mounted with 50 MOSFETs in various organ positions. 


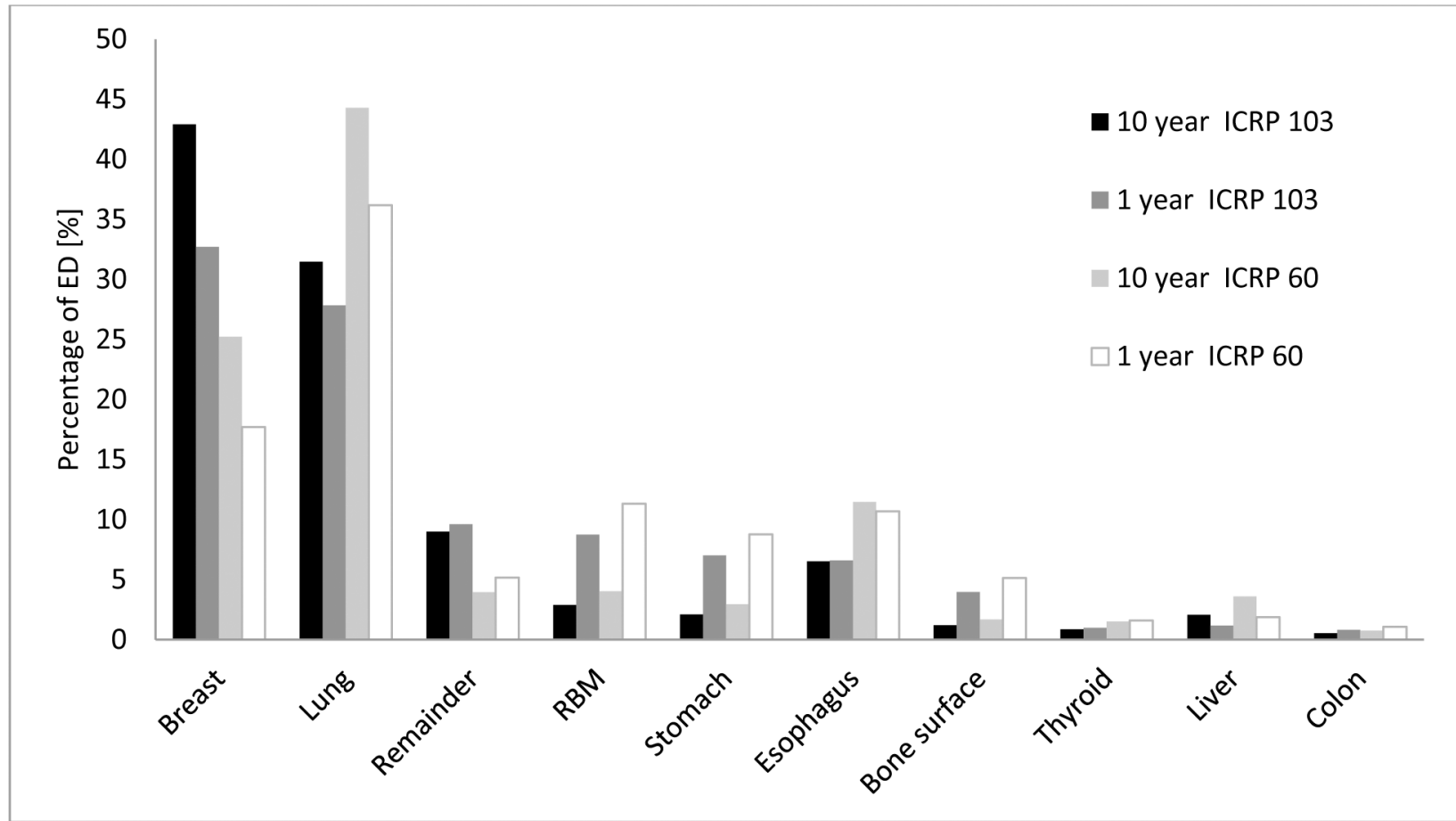

Fig 2:

Equivalent dose distribution in individual organs*, expressed as the percentage of ED, computed according to ICRP 103 and ICRP 60 protocols, for 1- and 10-year-old phantoms. Percentage represents average across different scan modes.

*Gonads, bladder, salivary glands and brain were not included, having each less than $0.5 \%$ of the ED. 
Table 1:

A list of organs that were measured in 1- and 10-year-old phantoms. For each organ, the number of assigned MOSFETs and the tissue weighting factors are specified based on ICRP Publication 103 and ICRP Publication 60 definitions, as well as the f-factors for the effective energy of 80,100 and $120 \mathrm{kVp}$.

\begin{tabular}{|c|c|c|c|c|c|c|c|}
\hline \multirow{2}{*}{ Organ $^{*}$} & \multirow{2}{*}{$\begin{array}{l}\text { Number of } \\
\text { MOSFETs } \\
1 \text { year old } \\
\text { phantom }\end{array}$} & \multirow{2}{*}{$\begin{array}{c}\text { Number of } \\
\text { MOSFETs } \\
10 \text { year old } \\
\text { phantom }\end{array}$} & \multirow{2}{*}{$\begin{array}{c}\text { Tissue } \\
\text { Weighting } \\
\text { factor } \\
\text { ICRP 103 }\end{array}$} & \multirow{2}{*}{$\begin{array}{c}\text { Tissue } \\
\text { Weighting } \\
\text { factor } \\
\text { ICRP 60 }\end{array}$} & \multicolumn{3}{|c|}{$\begin{array}{l}\text { f-factor for effective energy } \\
\text { for each tube potential }\end{array}$} \\
\hline & & & & & $80 \mathrm{kVp}$ & $100 \mathrm{kVp}$ & $120 \mathrm{kVp}$ \\
\hline Brain & 6 & 3 & 0.01 & In remainder & 1.0686 & 1.0745 & 1.0789 \\
\hline Salivary gland & 1 & 1 & 0.01 & - & 1.0601 & 1.0663 & 1.0710 \\
\hline Red Bone Marrow (RBM) & 14 & 14 & 0.12 & 0.12 & 1.0601 & 1.0663 & 1.0710 \\
\hline Bone surface & 14 & 14 & 0.01 & 0.01 & 6.1499 & 5.4305 & 4.8774 \\
\hline Thyroid & 1 & 2 & 0.04 & 0.05 & 1.0601 & 1.0663 & 1.0710 \\
\hline Lung & 5 & 5 & 0.12 & 0.12 & 1.0691 & 1.0738 & 1.0775 \\
\hline Esophagus & 3 & 4 & 0.04 & 0.05 & 1.0601 & 1.0663 & 1.0710 \\
\hline Breast & 1 & 1 & 0.12 & 0.05 & 0.8719 & 0.9079 & 0.9346 \\
\hline Stomach & 1 & 1 & 0.12 & 0.12 & 1.0601 & 1.0663 & 1.0710 \\
\hline Liver & 3 & 3 & 0.04 & 0.05 & 1.0601 & 1.0663 & 1.0710 \\
\hline Colon & 3 & 4 & 0.12 & 0.12 & 1.0601 & 1.0663 & 1.0710 \\
\hline Bladder & 1 & 2 & 0.04 & 0.05 & 1.0601 & 1.0663 & 1.0710 \\
\hline Ovaries/Testes & 2 & 2 & 0.08 & 0.20 & $\begin{array}{l}1.0571 / \\
1.0478\end{array}$ & $\begin{array}{l}1.0638 / \\
1.0561\end{array}$ & $\begin{array}{l}1.0689 / \\
1.0624\end{array}$ \\
\hline Remainder ${ }^{* *}$ & 11 & 13 & 0.12 & 0.05 & 1.0601 & 1.0663 & 1.0710 \\
\hline
\end{tabular}

* Skin was not included.

** Remainder ICRP 103 included: adrenals, extrathoracic (ET) region, gall bladder, heart, kidneys, oral mucosa, pancreas, prostate, small intestine, spleen, thymus, uterus/cervix, without lymphatic nodes and muscle. Remainder ICRP 60 included: adrenals, brain, upper large intestine, small intestine, kidneys, muscle, pancreas, spleen, thymus and uterus. 
Table 2:

Conversion factors for cardiac CT scans in 1- and 10- year-old phantoms using both ICRP Publication 103 and ICRP Publication 60 definitions of ED. All scans utilized a rotation time 0.35 seconds, a small scanning field of view (SFOV) and collimation of $64 \times 0.625 \mathrm{~mm}$ except for Calcium Score scan indicating $32 \times 0.625 \mathrm{~mm}$ collimation. The scanner reported DLP for all scans was based on the $32 \mathrm{~cm}$ CTDI phantom. Scan lengths for 1- and 10-year-old phantoms were $69.4 \mathrm{~mm}$ and $105.5 \mathrm{~mm}$, respectively; n/a denotes not applicable.

\begin{tabular}{|c|c|c|c|c|}
\hline Scan Description & Tube Potential [kVp] & Pitch & $\begin{array}{c}\text { Conversion factor } \\
\text { ICRP } 103 \\
{\left[\mathrm{mSv} \cdot \mathrm{mGy}^{-1} \cdot \mathrm{cm}^{-1}\right]}\end{array}$ & $\begin{array}{c}\text { Conversion factor } \\
\text { ICRP } 60 \\
{\left[\mathrm{mSv} \cdot \mathrm{mGy}^{-1} \cdot \mathrm{cm}^{-1}\right]}\end{array}$ \\
\hline \multicolumn{5}{|l|}{1 year old phantom } \\
\hline Axial & 80 & $\mathrm{n} / \mathrm{a}$ & 0.1001 & 0.0765 \\
\hline Axial & 100 & $\mathrm{n} / \mathrm{a}$ & 0.1012 & 0.0760 \\
\hline Axial with padding (100 ms) & 80 & $\mathrm{n} / \mathrm{a}$ & 0.1027 & 0.0776 \\
\hline Axial with padding (100 ms) & 100 & $\mathrm{n} / \mathrm{a}$ & 0.1011 & 0.0755 \\
\hline Helical & 80 & 0.24 & 0.0991 & 0.0787 \\
\hline Helical & 100 & 0.24 & 0.0931 & 0.0745 \\
\hline Helical TCM ${ }^{\ddagger}$ & 80 & 0.24 & 0.0972 & 0.0780 \\
\hline Helical TCM & 100 & 0.24 & 0.0955 & 0.0752 \\
\hline \multicolumn{5}{|l|}{10 year old phantom } \\
\hline Axial & 80 & $\mathrm{n} / \mathrm{a}$ & 0.0556 & 0.0378 \\
\hline Axial & 100 & $\mathrm{n} / \mathrm{a}$ & 0.0552 & 0.0373 \\
\hline Axial & 120 & $\mathrm{n} / \mathrm{a}$ & 0.0569 & 0.0387 \\
\hline Axial with padding (100 ms) & 80 & $\mathrm{n} / \mathrm{a}$ & 0.0566 & 0.0371 \\
\hline Axial with padding (100 ms) & 100 & $\mathrm{n} / \mathrm{a}$ & 0.0544 & 0.0373 \\
\hline Axial with padding (100 ms) & 120 & $\mathrm{n} / \mathrm{a}$ & 0.0544 & 0.0375 \\
\hline Helical & 120 & 0.22 & 0.0430 & 0.0320 \\
\hline Helical & 100 & 0.22 & 0.0441 & 0.0327 \\
\hline Helical & 80 & 0.22 & 0.0425 & 0.0312 \\
\hline Helical TCM ${ }^{*}$ & 120 & 0.22 & 0.0433 & 0.0319 \\
\hline Helical TCM ${ }^{*}$ & 100 & 0.22 & 0.0427 & 0.0318 \\
\hline Helical TCM ${ }^{*}$ & 80 & 0.22 & 0.0415 & 0.0305 \\
\hline Calcium Score $32 \times 0.625 \mathrm{~mm}$ collimation & 120 & $\mathrm{n} / \mathrm{a}$ & 0.0458 & 0.0327 \\
\hline Calcium Score $64 \times 0.625 \mathrm{~mm}$ collimation & 120 & $\mathrm{n} / \mathrm{a}$ & 0.0461 & 0.0332 \\
\hline
\end{tabular}

Tube current modulation 
Table 3:

Calculated EDs and conversion factors of six scan modes run with four different heart rates on a 1-year-old phantom. ED was determined using ICRP Publication 103 definition. CoVs of these quantities per scan mode are presented in percentage. For single-beat reconstruction [Snapshot Segment], 2-beat multicycle reconstruction [Snapshot Burst], and up to 4-beat multicycle reconstruction [Snapshot Burst Plus]. Three helical scans with 90-bpm were performed with a tube current three times that of the tube current of other heart rate scans, affecting the ED values. Assuming linearity of dose with tube current, we normalized the EDs, dividing by a factor of 3 to compare with EDs of the other heart rate scans; the normalized ED values are displayed in parentheses.

\begin{tabular}{|c|c|c|c|c|c|}
\hline Scan Description & $\begin{array}{l}\text { Heart } \\
\text { Rate } \\
\text { (bpm) }\end{array}$ & $\begin{array}{c}\text { Conversion } \\
\text { factor } \\
\left(\mathbf{m S v} \cdot \mathbf{m G y}^{-1} \cdot \mathbf{c m}^{-1}\right)\end{array}$ & $\begin{array}{c}\text { CoV }^{*} \\
\text { Conversion } \\
\text { factor }(\%)\end{array}$ & $\underset{(\mathbf{m S v})}{\text { ED }}$ & $\begin{array}{c}\text { CoV }^{*} \\
\mathbf{E D}(\%)\end{array}$ \\
\hline \multirow{4}{*}{ Axial } & 90 & 0.0940 & \multirow{4}{*}{5.59} & 2.9 & \multirow{4}{*}{5.59} \\
\hline & 110 & 0.1019 & & 3.2 & \\
\hline & 130 & 0.1067 & & 3.3 & \\
\hline & 150 & 0.1053 & & 3.3 & \\
\hline \multirow{4}{*}{$\begin{array}{c}\text { Axial } \\
\text { Padding } 100 \mathrm{~ms}\end{array}$} & 90 & 0.0985 & \multirow{4}{*}{1.39} & 5.6 & \multirow{4}{*}{1.39} \\
\hline & 110 & 0.0984 & & 5.6 & \\
\hline & 130 & 0.1014 & & 5.8 & \\
\hline & 150 & 0.0993 & & 5.6 & \\
\hline \multirow{4}{*}{$\begin{array}{c}\text { Helical } \\
\text { Single-beat } \\
\text { Reconstruction }\end{array}$} & 90 & 0.0919 & \multirow{4}{*}{1.16} & $(7.5)$ & \multirow{4}{*}{1.16} \\
\hline & 110 & 0.0896 & & 7.3 & \\
\hline & 130 & 0.0897 & & 7.4 & \\
\hline & 150 & 0.0903 & & 7.4 & \\
\hline \multirow{4}{*}{$\begin{array}{c}\text { Helical } \\
\text { 2-beat Multicycle } \\
\text { Reconstruction }\end{array}$} & 90 & 0.0907 & \multirow{4}{*}{1.52} & (8.1) & \multirow{4}{*}{5.29} \\
\hline & 110 & 0.0912 & & 7.5 & \\
\hline & 130 & 0.0889 & & 7.3 & \\
\hline & 150 & 0.0884 & & 7.3 & \\
\hline \multirow{4}{*}{$\begin{array}{c}\text { Helical } \\
\text { Up to 4-beat Multicycle } \\
\text { Reconstruction }\end{array}$} & 90 & 0.0925 & \multirow{4}{*}{1.45} & $(9.5)$ & \multirow{4}{*}{4.36} \\
\hline & 110 & 0.0911 & & 9.6 & \\
\hline & 130 & 0.0905 & & 8.9 & \\
\hline & 150 & 0.0893 & & 8.8 & \\
\hline \multirow[t]{4}{*}{ Helical TCM ${ }^{* *}$} & 90 & 0.0959 & 2.35 & 6.2 & 3.79 \\
\hline & 110 & 0.0930 & & 5.8 & \\
\hline & 130 & 0.0924 & & 5.9 & \\
\hline & 150 & 0.0906 & & 6.3 & \\
\hline
\end{tabular}

* Coefficient of variation

Tube Current modulation 
Table 4:

Conversion factors for cardiac CT scans in 1-year-old phantom, based on dosimetry from 16-17 MOSFETs in the phantom, in three sub-experiments, using both ICRP Publication 103 and ICRP Publication 60 definitions of ED. The percentage difference for each scan is presented, comparing between a conversion factor derived using 50 MOSFETs per measurement (Table 2) vs. a conversion factor derived using 16-17 MOSFETs in three sets of measurements. All scans utilized a rotation time of 0.35 seconds, a small scan field of view (SFOV), scan length of $69.4 \mathrm{~mm}$, and collimation of $64 \times 0.625 \mathrm{~mm}$. The scanner-reported DLP for all scans was based on the $32 \mathrm{~cm}$ CTDI phantom; n/a denotes not applicable.

\begin{tabular}{|c|c|c|c|c|c|c|}
\hline Scan Description & $\begin{array}{c}\text { Tube } \\
\text { Potential } \\
{[\mathrm{kVp}]}\end{array}$ & Pitch & $\begin{array}{l}\text { Conversion factor } \\
\text { ICRP } 103 \\
{\left[\mathrm{mSv} \cdot \mathrm{mGy}^{-1} \cdot \mathrm{cm}^{-1}\right]}\end{array}$ & $\begin{array}{c}\text { \% difference } \\
\text { from 50 } \\
\text { MOSFETs } \\
\text { conversion factor } \\
\text { (Table 2) }\end{array}$ & $\begin{array}{c}\text { Conversion factor } \\
\text { ICRP 60 } \\
{\left[\mathrm{mSv}^{-} \mathbf{m G y}^{-1} \cdot \mathrm{cm}^{-1}\right]}\end{array}$ & $\begin{array}{c}\text { \% difference } \\
\text { from 50 } \\
\text { MOSFETs } \\
\text { conversion factor } \\
\text { (Table 2) }\end{array}$ \\
\hline Axial & 80 & $\mathrm{n} / \mathrm{a}$ & 0.1001 & 1.79 & 0.0765 & 7.68 \\
\hline Axial & 100 & $\mathrm{n} / \mathrm{a}$ & 0.1012 & 3.85 & 0.0760 & 6.40 \\
\hline Axial with padding (100 ms) & 80 & $\mathrm{n} / \mathrm{a}$ & 0.1027 & -6.22 & 0.0776 & -1.20 \\
\hline Axial with padding (100 ms) & 100 & $\mathrm{n} / \mathrm{a}$ & 0.1011 & -6.26 & 0.0755 & -1.96 \\
\hline Helical & 80 & 0.24 & 0.0991 & -1.67 & 0.0787 & -1.85 \\
\hline Helical & 100 & 0.24 & 0.0931 & -1.50 & 0.0745 & 0.27 \\
\hline Helical TCM * & 80 & 0.24 & 0.0972 & -0.89 & 0.0780 & -0.25 \\
\hline Helical TCM * & 100 & 0.24 & 0.0955 & -0.58 & 0.0752 & 1.23 \\
\hline
\end{tabular}

* TCM denotes tube current modulation 
Table 5:

Average pediatric cardiac and chest conversion factors that have been published in recent years, and cardiac conversion factors of this study, for 1-year-old and 10-year-old children.

\begin{tabular}{|c|c|c|c|c|c|c|c|c|c|}
\hline $\begin{array}{c}\text { Age } \\
\text { (years) }\end{array}$ & $\begin{array}{c}\text { Scan } \\
\text { Region }\end{array}$ & $\begin{array}{l}\text { Scan } \\
\text { Length } \\
\text { (cm) }\end{array}$ & $\begin{array}{c}\text { Conversion } \\
\text { Factor }(\text { mean }) \\
(\mathbf{m S v} \cdot \mathbf{m G y} \\
\left.{ }^{1} \cdot \mathbf{c m}^{-1}\right)\end{array}$ & $\begin{array}{l}\text { CTDI Phantom } \\
\text { size }(\mathrm{cm})\end{array}$ & $\begin{array}{c}\begin{array}{c}\text { Conversion } \\
\text { Factor } \\
\text { (mean) }\end{array} \\
\text { Normalized } \\
\text { to } \\
32 \mathrm{~cm} \\
\text { phantom }\end{array}$ & $\begin{array}{c}\text { ICRP } \\
\text { Publication } \\
\text { ED } \\
\text { Definition }\end{array}$ & Scanner Model & $\begin{array}{l}\text { No. of } \\
\text { Scanner } \\
\text { Slices }\end{array}$ & Reference \\
\hline 1 & Cardiac & 6.9 & 0.099 & 32 & 0.099 & 103 & GE LightSpeed VCT XTe & 64 & This Study \\
\hline 1 & Cardiac & 10 & 0.046 & 16 & 0.092 & 103 & Toshiba Aquilion ONE & 320 & $\begin{array}{l}\text { Podberesky } \\
\text { et al [22] }\end{array}$ \\
\hline 1 & Chest & 10.75 & 0.0482 & 32 & 0.0482 & 103 & $\begin{array}{l}\text { Siemens Somatom } \\
\text { Sensation }\end{array}$ & 64 & $\begin{array}{l}\text { Deak et al } \\
{[19]}\end{array}$ \\
\hline 1 & Chest & 12 & 0.038 & 16 & 0.072 & 103 & GE LightSpeed VCT & 64 & $\begin{array}{l}\text { Allesio et } \\
\text { al [29] }\end{array}$ \\
\hline 1 & Cardiac & 6.9 & 0.076 & 32 & 0.076 & 60 & GE LightSpeed VCT XTe & 64 & This Study \\
\hline 1 & Chest & 10.75 & 0.0443 & 32 & 0.0443 & 60 & $\begin{array}{l}\text { Siemens Somatom } \\
\text { Sensation }\end{array}$ & 64 & $\begin{array}{l}\text { Deak et al } \\
{[19]}\end{array}$ \\
\hline 1 & Chest & 12 & 0.026 & 16 & 0.049 & 60 & $\begin{array}{l}\text { Siemens DRH, GE } 9800 \text { and } \\
\text { Philips LX } 3 \text { first generation } \\
\text { scanners }\end{array}$ & 1 & $\begin{array}{l}\text { Shrimpton } \\
\text { et al [18, } \\
\text { 32] }\end{array}$ \\
\hline 10 & Cardiac & 10.55 & 0.049 & 32 & 0.049 & 103 & GE LightSpeed VCT XTe & 64 & This Study \\
\hline 10 & Chest & 17.75 & 0.0237 & 32 & 0.0237 & 103 & Siemens Somatom Sensation & 64 & $\begin{array}{l}\text { Deak et al } \\
{[19]}\end{array}$ \\
\hline 10 & Chest & 20 & 0.019 & 16 & 0.036 & 103 & GE LightSpeed VCT & 64 & $\begin{array}{l}\text { Allesio et } \\
\text { al [29] }\end{array}$ \\
\hline 10 & Cardiac & 10.55 & 0.034 & 32 & 0.034 & 60 & GE LightSpeed VCT XTe & 64 & This Study \\
\hline 10 & Chest & 17.75 & 0.0221 & 32 & 0.0221 & 60 & Siemens Somatom Sensation & 64 & $\begin{array}{l}\text { Deak et al } \\
{[19]}\end{array}$ \\
\hline 10 & Chest & 20 & 0.013 & 16 & 0.025 & 60 & $\begin{array}{l}\text { Siemens DRH, GE } 9800 \text { and } \\
\text { Philips LX } 3 \text { first generation } \\
\text { scanners }\end{array}$ & 1 & $\begin{array}{l}\text { Shrimpton } \\
\text { et al }[18 \text {, } \\
32]\end{array}$ \\
\hline
\end{tabular}

Normalization by a factor of 1.9 [22] 